\title{
MÚSICA MILITAR EN COSTA RICA DURANTE LA PRIMERA MITAD DEL SIGLO XX: DISTRIBUCIÓN DE CONOCIMIENTO, VALORES ESTÉTICOS Y PATRIOTISMO
}

\author{
Military music in Costa Rica during the first half of the 20th century: \\ distribution of knowledge, aesthetic values and patriotism
}

\author{
Mauricio Araya Quesada \\ Universidad de Costa Rica, Costa Rica \\ mauarayacr@gmail.com
}

Recibido: $30-09-2017$

Aprobado: 26-02-2018

Mauricio Araya Quesada es Magíster en Música con énfasis en Dirección de Banda. Profesor en la Sede de Occidente de la Universidad de Costa Rica, Departamento de Filosofía, Artes y Letras. Fue director titular de la Banda de Conciertos de Alajuela y fungió como Director General de Bandas del Gobierno de Costa Rica.

\section{RESUMEN}

En dos artículos publicados se discutió sobre la importancia de las bitácoras de trabajo de la Banda Militar de Alajuela y los datos suministrados por ellas. El primero, introductorio, con resultados preliminares; el segundo, con un marco histórico de referencia y resultados estadísticos extraídos del repertorio ejecutado. Esta tercera entrega ampliará la discusión sobre el significado "banda militar" en Costa Rica y su papel en la distribución de conocimiento musical y valores estéticos. El texto pondrá disponible más información sobre personajes ligados a las bandas; además, algunos documentos utilizados como ilustraciones aportaran datos sujetos a un análisis que permitirá saber más sobre la música en Costa Rica entre 1938 y 1946, la labor de sus Bandas Militares, alcance y su contacto con la población.

Palabras clave: música costarricense; historia de Costa Rica; Bandas del gobierno de Costa Rica; cultura musical de Costa Rica; Banda Militar de Alajuela

\begin{abstract}
The importance of the Alajuela Military Band logbooks, and the information contained therein, has been discussed in two published articles. The first is an introduction, with preliminary results, and the second, presents a historical frame of reference and statistical results taken from the repertoire performed. This third article will further discuss just what a Costa Rican "military band" is and its role in the dissemination of musical knowledge and aesthetic values. The article will also include information about different personalities associated to these bands. In addition, an analysis of data obtained from documents used as illustrations will give us a better understanding of music in Costa Rica, between 1938 and 1946, in terms of Military Bands and the extent of their contact with the population.
\end{abstract}

Keywords: Costa Rican music; history of Costa Rica; Costa Rican government bands; Costa Rican musical culture; Military Band of Alajuela 
En dos artículos escritos anteriormente se discutió sobre la importancia de las bitácoras de trabajo de la Banda Militar de Alajuela y los datos suministrados por ellas. El primero fue un artículo introductorio que contiene algunos antecedentes históricos de lo administrativo y lo jurídico; un estado de la cuestión con información sobre los principales libros escritos que hablan sobre las bandas militares de Costa Rica; una introducción sobre las posibles categorías de análisis, la metodología y algunos resultados preliminares que contemplaron listados de compositores y obras que no se encuentran en las publicaciones sobre la historia musical costarricense. El segundo, contiene el marco histórico de referencia de la Banda Militar de Alajuela y un análisis de resultados estadísticos extraídos del repertorio ejecutado. ${ }^{1}$

Esta tercera entrega amplía la discusión sobre el significado "banda militar" en Costa Rica, y muestra los antecedentes históricos y conceptuales de los formatos instrumentales. También, el texto ofrece información histórica de otros autores, sobre personajes y detalles de la situación administrativa, con el fin de brindar un panorama general de la cuestión, en especial a aquellos lectores que no han tenido la oportunidad de conocer sobre la historiografía de las bandas militares de Costa Rica en la primera mitad del siglo XX. Luego, se aportan algunas ideas sobre cómo esos grupos musicales participaron en la distribución de conocimiento musical, valores estéticos y patriotismo. Algunos documentos utilizados como ilustraciones aportan datos, que sujetos a un análisis, permiten saber más sobre la música en Costa Rica entre 1930 y 1946, desde el campo de sus bandas militares y el alcance de éstas en contacto con la población. Se debe aclarar que esa delimitación temporal se da porque los documentos y datos analizados son de ese periodo.

Es importante comenzar con un breve repaso de la historia de los formatos instrumentales que antecedieron a las bandas militares de la época delimitada, para introducir el concepto desarrollado en Costa Rica; éste, como se podrá observar, es reflejo de la realidad histórica del país. Además, los datos sobre las sucesiones administrativas de la Dirección General de Bandas sirven para dar a conocer a los personajes de alto rango involucrados, quienes tenían la máxima

\footnotetext{
${ }^{1}$ Mauricio Araya, "La Banda Militar de Alajuela y su papel como difusora de música nacional. Análisis de las bitácoras de trabajo 1938-1946. Introducción y resultados preliminares". Universidad de Costa Rica-Sede de Occidente, Revista Pensamiento Actual 16, n. ${ }^{\circ} 27,(2016):$ 71-97

Mauricio Araya. "La Banda Militar de Alajuela y su papel como defensora de la música nacional entre 19381946. Análisis de las bitácoras de trabajo". Universidad de Costa Rica, Revista Herencia 30, n. 1 (2017): 154176.
} 
cuota de poder en la organización, para proponer y ejecutar iniciativas que afectaron el acercamiento de las agrupaciones con su público. Todo lo anterior propicia una discusión en donde se puedan establecer ejemplos concretos de cómo en la relación bandas-población interactuaron cultura, educación y poder.

Las fuentes documentales brindan basta información que deberá presentarse, debido a la necesidad de tenerla a mano, porque que no está en los textos sobre la música en Costa Rica en la primera mitad del siglo XX. Por lo tanto, y ante la brevedad de este escrito; los datos e ilustraciones serán acompañados de comentarios, que permitan continuar la discusión en proyectos posteriores, en temas específicos como: repertorios, obras, autores, influencias internacionales, etc.

\section{Bandas en Europa}

Las bandas militares estaban conformadas por instrumentos de viento y percusión, la cantidad de integrantes dependía de diversos factores históricos, económicos, sociales y políticos. Según el diccionario compilado por Latham Alison, Diccionario enciclopédico de la música, una banda es:

\footnotetext{
Grupo de instrumentos. Inicialmente, el término fue utilizado para cualquier grupo, sin embargo, hoy día existe una distinción algo esnob entre orquestas y bandas. Las bandas de metal sólo [sic] usan instrumentos de boquilla circular (además de percusiones). Las bandas de vientos o de concierto, también denominadas orquestas de vientos, incluyen todos los alientos y percusiones y se derivan de las bandas militares... ${ }^{2}$
}

Los antecedentes de las bandas de instrumentos de viento y percusión se encuentran en los formatos instrumentales utilizados en lo que se denominó Harmoniemusik. Desde la "Alta Capella" que evolucionó a partir del siglo XIII con una chirimía, un bajón, un corneto, un sacabuche y bombardas, luego en el barroco algunas composiciones de G. Gabrieli y M. Praetorius para grupos de viento, también J. F. Fasch, J. D. Zelenka o Rodríguez de Hita, con obras para grupos de oboes, trompas y fagot. Para el año 1663 se sabe de la existencia de bandas en los regimientos prusianos. Un ensamble con dos oboes, dos fagots, dos clarinetes y dos cornos fue estabilizado en la corte de Federico de Prusia. En ese mismo lugar, en los inicios del siglo XVIII (1705) se conoció una banda de oboes y trompetas. También, en 1761 el príncipe Paul Antón Esterházy mantuvo

${ }^{2}$ Alison Latham, Diccionario enciclopédico de la música (México D.F: Fondo de Cultura Económica, 2008), p. 151. 
un sexteto de dos oboes, dos trompas y dos fagotes. Posteriormente, el octeto formado por dos oboes, dos clarinetes, dos trompas y dos fagotes fue introducido en el centro de Europa por el príncipe Schwarzenberg hacia 1776.

Haydn, Mozart, C.P.E. Bach y Beethoven crearon obras para ensambles de viento en el siglo XVIII y además realizaron algunas anotaciones sobre ese formato instrumental. El emperador José Il de Habsburgo (1741-1790) fundó en 1782 la Königliche Kaiserliche Harmonie y contrató a los instrumentistas de viento más connotados del momento: Georg Triebensee y Johann N. Wendt (oboes), los hermanos Stadler (clarinetes), Rupp y Eisen (trompas), Kauzner y Drobney (fagotes). Estos intérpretes también eran arreglistas y compositores especializados en Harmoniemusik. Otros aristócratas que apoyaron esos ensambles instrumentales fueron el príncipe Nikolaus Esterházy, el príncipe Alois I de Liechtenstein, el archiduque Maximilian Franz de Austria, elector de Colonia y el príncipe Lobkowitz en Praga.

La música de los grupos de vientos funcionó como acompañamiento de fondo en actividades sociales: serenata para los nobles y para acompañar banquetes (Taffelmusik). Serenatas y divertimentos fueron escritos originalmente para esos formatos instrumentales, también transcripciones de óperas, sinfonías y ballets. Para el siglo XIX, los grupos aumentaron de tamaño y obras como la Obertura opus 24 de Mendelssohn, la Serenata para vientos de Dvorak, la Trauersimponie de Wagner y las Serenatas para vientos de Strauss, fueron abriendo camino a formatos parecidos a los actuales desde los últimos años del siglo XIX y la primera década del XX.

Las innovaciones instrumentales de Adolph Sax en Francia y Wieprecht en Alemania, hacia 1845 fueron muy influyentes. Aparecieron nuevos instrumentos, más versátiles y con mejor tecnología, lo que dio pie a que los grupos aumentaran y mejoraran, de forma que se constituían en bandas mucho más numerosas. Ya para el siglo XX se fue creando un repertorio de composiciones exclusivas para bandas de viento por autores de gran renombre, sobre todo desde la década de 1920; ejemplo de ello las obras de compositores como Holst, Hindemith, Prokofiev, Krenek, Stravinsky, Milhaud, Barber y otros que empezaron a componer para ese medio instrumental. ${ }^{3}$

\footnotetext{
${ }^{3}$ Algunos datos fueron extraídos de: Bartolomé Mayor Catalá, "Harmoniemusik," Sinfonía Virtual, no. 21 (2011): http://www.sinfoniavirtual.com/revista/021/harmoniemusik.php

Mayor Catalá es máster en "Creación e Interpretación Musical" en la Universidad Rey Juan Carlos de Madrid y profesor de fagot en el Real Conservatorio Superior de Música "Victoria Eugenia" de Granada.
} 
Un modelo de instrumentación utilizado por Gustav Holst en su primera suite para banda militar, compuesta en 1909 y publicada por primera vez en 1921; fue el siguiente:

- Maderas: Flauta/Píccolo en Db, 2 Clarinetes en Eb, 2 Oboes, Clarinete Solo en $\mathrm{Bb}$, Primeros Clarinetes en Bb, Segundos Clarinetes en Bb, Terceros Clarinetes en Bb, Clarinete bajo en Bb, 2 Fagots, Saxofón Alto en Eb, Saxofón Tenor en Bb.

- Metales: Primer Corneta en Bb, Segundas Cornetas en Bb, 2 Trompetas en Eb, 2 Trompetas en Bb, 2 Cornos en Eb, 2 Cornos en F, Barítono en Bb, 2 Trombones Tenores, Trombón Bajo, Eufonio en Bb, Bombardones (un tipo de tuba antigua).

- Percusión: Timbales Sinfónicos, Redoblante, Bombo, Platillos de choque, Triángulo, Pandereta.

- Cuerdas: Contrabajo. ${ }^{4}$

\section{Bandas militares en Costa Rica}

Las bandas militares de Costa Rica iniciaron su proceso de desarrollo desde antes de 1845 y poco a poco se fueron estabilizando una en cada provincia. Incluso de manera temporal se estableció una en la ciudad de San Ramón pero no prosperó y desapareció. ${ }^{5}$ Desde 1845 fueron supervisadas por el gobierno central, de tal manera que se logró consolidar la Dirección General de Bandas del Departamento de Guerra y Marina. Después de 1948, debido a la abolición del ejército, esos grupos se trasladaron al Ministerio de Seguridad Pública, dejaron su carácter militar y se les dio el nombre de Bandas Nacionales. En 1972, se dispuso realizar el traslado del cuerpo de bandas al Ministerio de Cultura, Juventud y Deportes y a partir del año 2009, por razones estratégicas relacionadas con la imagen y la publicidad de las mismas, se les denominó Bandas de Conciertos. ${ }^{6}$

También de: Frederick Fennell, Time and the winds, a Short History of the Use of Wind Instruments in The Orquestra, Band and The Wind Ensamble. (Northland Music Publishers, 2009).

${ }^{4}$ Esmail Khalili, Gustav Holst's Suite In E-Flat, OP. 28: A comparative Analysis of the Original Manuscript and Later Editions. An adapted online version of a paper submitted in partial fulfillment of the requirements for the Master of Music degree in Instrumental Conducting. The Wind Repertory Project, (2009). http://www.windrep.org/Articles:First_Suite\#PART_II.E2.80.93_HOLST.E2.80.99S_1909_MANUSCRIPT:_A DETAILED_ANALYSIS

5 Pompilio Segura Chaves, Desarrollo musical en Costa Rica durante el siglo XIX. Las Bandas militares. (Heredia: Editorial de la Universidad Nacional, 2001), 181-182.

6 Más información sobre la base histórico-administrativa de las bandas en: Procuraduría General de la República. Dictamen 198 del 18 de mayo de 2006. Dirigido a la ministra de cultura María Elena Carballo 
Las bandas comenzaron a tener una presencia importante ya entrado el siglo XIX. Pompilio Segura afirma que, antes del año 1840,

...hubo bandas militares, pero no producían música, solo eran conjuntos de tambores, clarines y cornetas, destinados a disciplinar las milicias en sus diferentes marchas y movimientos, a ejecutar los toques de ordenanza y ofrecían a la vez perfecto ritmo marcial para que los soldados pudieran marchar con toda regularidad. ${ }^{7}$

Los siguientes trabajos investigativos, también mencionados en publicaciones anteriores, describen sucesos históricos desde varias perspectivas y en diferentes contextos. Una vez más, vale la pena mencionar sus aportes y agregar otros ubicados posteriormente, para ir ampliando la discusión y dejar disponibles más datos que se sumen a los existentes.

En principio podríamos mencionar de Pompilio Segura El desarrollo musical en Costa Rica durante el siglo XIX: Las bandas militares. Esta obra es la más enfocada en la historiografía de las bandas y describe los sucesos de las siete bandas de cada provincia más la de San Ramón. Su delimitación temporal va desde la segunda mitad del siglo XIX hasta inicios del siglo XX. ${ }^{8}$

Manuel María Gutiérrez, de Carlos Meléndez Chaverri, cuenta la historia de ese personaje ligado de por vida al sistema de bandas, pues fue músico, director y director general. Eso lo llevó a ser protagonista de sucesos históricos sobresalientes como la Batalla de Rivas, la composición del Himno Nacional y algunos viajes al exterior. El periodo histórico que aborda va desde antes de 1840 hasta 1887.9

La Familia Morales: Músicos por tradición, de Roberto Le Franc Ureña, recorre las biografías de los músicos de esa familia, quienes tuvieron un ligamen con las bandas militares; también incluye al final información sobre Manuel María Gutiérrez. $^{10}$

Juan Loots y las bandas de música militar de Ludmila Svatec presenta datos sobre las bandas desde finales del siglo XIX hasta el primer tercio del siglo XX.

Castegnaro, en respuesta al oficio DM-574-2005 del 29 de abril del 2005, signado por el anterior Ministro, Sr. Guido Sáenz González.

${ }^{7}$ Segura, Desarrollo musical en Costa Rica durante el siglo XIX, 42.

8 Pompilio Segura Chaves, Desarrollo musical en Costa Rica durante el siglo XIX. Las Bandas militares (Heredia: Editorial de la Universidad Nacional, 2001).

${ }^{9}$ Carlos Meléndez, Manuel María Gutiérrez (San José: Ministerio de Cultura, Juventud y Deportes. Depto. de Publicaciones, 1979).

${ }^{10}$ Roberto Le Franc, La familia Morales: músicos por tradición (San José, C.R: Editorial UCR, 2009). 
Si bien mucha de la información es relevante, la autora no colocó citas ni bibliografía de tal manera que no se puede saber de dónde proviene. Al parecer indagó en varios documentos como las bitácoras, pero no las citó. ${ }^{11}$

De las Fanfarrias a las salas de conciertos, música en Costa Rica (1840-1940), libro escrito por María Clara Vargas Cullell, coloca apartados sobre las bandas militares: uno sobre acontecimientos entre 1845 y 1970, otro sobre los recreos, las retretas y la problemática de los músicos militares y filarmónicos. ${ }^{12}$

Todos los anteriores escritos son las referencias que brindan los datos más antiguos. Otros investigadores que también han abordado el tema y contribuido con información son Bernal Flores y Gabriel Goñi Dondi. ${ }^{1314}$

Bernal Flores, en su libro Julio Fonseca, deja disponible en el anexo XIV una publicación de don Julio tomada de la Revista Musical, año II, 2 de julio de 1941, número 4. "Apuntes sobre música costarricense" y número dos, "Agrupaciones artísticas". Es pertinente señalar el conocimiento histórico de don Julio sobre las bandas militares. En unas pocas líneas encontramos detalles suministrados por él sobre personajes y la situación administrativa en general. Se menciona que hay una banda en cada provincia y que todas tienen treinta integrantes, excepto la de la capital, que cuenta con sesenta. También señala que el presupuesto empleado en ese momento era 12165 colones; sin embargo, no queda claro si éste pertenecía al presupuesto operativo total o únicamente al de remuneraciones. La Dirección General, dice Julio Fonseca, mantienen los grupos militarmente organizados y suplen partituras (lo que él llama archivo), materiales y la reposición de músicos cuando se pensionaban "por nuevos elementos que se forman en la escuela agregada ad-hoc a la Dirección General y fundada el año 1907, bajo la Administración González Víquez por insinuación del Director en esa época, el Maestro belga, don Juan Loots". ${ }^{15}$

Las fuentes mencionadas anteriormente indican quiénes estuvieron a cargo de la música marcial del Estado costarricense; saberlo es importante para reconocer a los actores principales, quienes tenían la mayor cuota de poder para tomar decisiones estratégicas, las mismas que impactaron directamente a la población a través de las presentaciones de las bandas militares.

\footnotetext{
11 Ludmila Svatec, Juan Loots y las bandas de música militar (San José: Ministerio de Cultura Juventud y Deportes. Instituto del libro, 1986),

12 María Clara Vargas, De las fanfarrias a las salas de concierto: música en Costa Rica, 1840-1940 (San José, Costa Rica: Editorial de la Universidad de Costa Rica, 2004).

${ }^{13}$ Bernal Flores, La música en Costa Rica (San José: Editorial Costa Rica, 1978).

14 Gabriel Goñi, Roberto Cantillano Vindas: compositor, director y flautista domingueño. La Retreta $1, \mathrm{n} .^{\circ} 3$ (2008): http://laretreta.net/0103/articulos/cantillano.html

15 Flores, Julio Fonseca, 299.
} 
Carlos Meléndez apunta que José María Martínez inició su labor como Director General de Bandas el primer día del año $1846^{16}$. Si bien algunos otros autores no lo denominan de esa manera, sí está claro que en varios decretos se describe su contratación y las obligaciones que adquirió para organizar la música militar del país. ${ }^{17}$ Nació en San Agustín, Florida, Estados Unidos. Viajó a Cuba, El Salvador, Guatemala y Costa Rica, en donde se estableció en noviembre de 1845 junto a su esposa, dos hijos (José y María Matea) y dos discípulos (Jacinto Pérez y Salvador Castillo). Murió el 30 de marzo 1852 siendo director de la Banda Militar de San José. ${ }^{18}$

Francisco Llibon, de origen guatemalteco, fue nombrado director de la música marcial del país en mayo de $1847^{19}$

Manuel María Gutiérrez (autor del Himno Nacional) sustituyó a Martínez como director de la Banda Militar de San José en abril de 1852. ${ }^{20}$ Fue director general desde 1852, según don Julio Fonseca ${ }^{21}$ y Marta Castegnaro citada por Robreto Le Franc. Carlos Meléndez también coincide con ellos al decir:22

...el Maestro Martínez murió en San José en el desempeño de su cargo, a principio del año 1852, hecho que para don Manuel María habría de significar su carrera de ascensos, al convertirse en su sucesor en el cargo de la Dirección General de Bandas..."23 [además detalla lo siguiente]: "... (José Martínez) se permitió antes de morir, recomendar al músico herediano como la persona más indicada para que le sucediera en el cargo de Director General de Bandas..., el propio don José Joaquín Mora Porras hermano del Presidente don Juanito Mora, le nombró en efecto como Director General de Bandas, el día 22 de marzo... ${ }^{24}$

Pompilio Segura también está de acuerdo en que fue nombrado en 1852 como director de la música marcial, sólo que desde el 22 de abril. ${ }^{25}$ Gutiérrez ocupó el cargo hasta el día 15 de diciembre de 1887 pues por problemas de salud, debió pedir un permiso. Fue sustituido en esa fecha en la dirección general por Rafael Chávez Torres. ${ }^{26}$

\footnotetext{
16 Meléndez, Manuel María Gutiérrez, 34.

17 Colección de Leyes y Decretos. Decreto LXIII (24 de diciembre, 1845), 208, 209.

18 Segura, Desarrollo musical en Costa Rica, 196-198.

19 Segura, Desarrollo musical en Costa Rica, 42.

Ese dato lo suministra también María Clara Vargas en su libro en la página 36.

20 Segura, Desarrollo musical en Costa Rica, 210.

${ }^{21}$ Flores, Julio Fonseca, 300.

22 Le Franc, La familia Morales, 123.

23 Meléndez, Manuel María Gutiérrez, 19.

24 Meléndez, Manuel María Gutiérrez, 36.

25 Segura, El desarrollo musical en Costa Rica, 159.

${ }^{26}$ Meléndez, Manuel María Gutiérrez, 81.
} 
Rafael Chávez Torres (compositor de la marcha fúnebre El Duelo de la Patria, compuesta para las ceremonias fúnebres del ex presidente Tomás Guardia Gutiérrez) fue director general de 1887 a 1907.

Alfredo Morales ${ }^{27}$ ocupó la dirección general de manera interina en 1907 hasta el nombramiento de Juan Loots. ${ }^{28}$

El músico belga Juan Bautista Ghislain Loots Deblaes (1907-1929) fue traído al país en la administración de González Víquez, don Julio Fonseca señala de éste: ${ }^{29}$

... quien con su valioso aporte de conocimientos y sus prendas de energía y disciplina, puso al Cuerpo de Bandas a una altura europea, siendo uno de sus más legítimos triunfos, el que su Banda fuera expresamente pedida de Panamá para los festejos en celebración de la ascensión al Poder del Presidente Porras. Por motivos de salud, el maestro Loots tuvo que regresar a su patria, y en su ausencia se encargaron sucesivamente de la Dirección los señores don Roberto Campabadal y don César Nieto. A su regreso, volvióle [sic] a ser encomendada la Dirección de Bandas. ${ }^{30}$

Roberto Cantillano dirigió de 1936 hasta 1948; sin embargo, como señala Gabriel Goñi

... con los disturbios de la Guerra Civil y en desacuerdo con los nuevos procesos políticos que acontecían en el país, el maestro Cantillano renuncia a su puesto como Director General de Bandas y se retira a su hogar concentrándose en sus clases de flauta hasta su muerte el 15 de noviembre, a los sesenta y ocho años, en $1955 .{ }^{31}$

Julio Fonseca, al igual que la mayoría de los investigadores, cuenta la existencia de la escuela de música militar fundada por Juan Loots en el gobierno de González Víquez. Ahí brindaban formación musical a los integrantes de los grupos en las diferentes especialidades instrumentales.

El Gobierno sostiene también una Escuela de Música Militar, fundada desde el año 1907, donde se elaboran nuevos músicos que van a llenar las plazas vacantes en los diferentes cuerpos de Bandas de la República. El presupuesto fijado para el sostenimiento de este centro es de $₫ 720.00$ mensuales, más gastos de subsistencia. Está agregada a la Dirección de Bandas y bajo las mismas reglas de disciplina militar. ${ }^{32}$

\footnotetext{
${ }^{27}$ Flores, Julio Fonseca, 300.

${ }^{28}$ Le Franc, La familia Morales, 104.

${ }^{29}$ Don Julio Fonseca escribe su apellido "Blaes" seguramente por error.

${ }^{30}$ Flores, Julio Fonseca, 300.

31 Gabriel Goñi, Roberto Cantillano Vindas: compositor, director y flautista domingueño. La Retreta 1, no. 3 (2008): http://laretreta.net/0103/articulos/cantillano.html

${ }^{32}$ Flores, Julio Fonseca, 304.
} 
El maestro Fonseca menciona que además de las bandas, existían grupos similares en otros contextos administrativos: "en la mayoría de las poblaciones de importancia, filarmonías sostenidas por las municipalidades locales; y la institución religiosa de los P. P. Salesianos tiene dos pequeñas bandas..."33

Con respecto al formato instrumental, la mayoría de las agrupaciones no contaban con todos los instrumentos necesarios, ni con la cantidad de músicos requeridos para conformar una banda completa (de acuerdo a la instrumentación sugerida por Holst en su Primera Suite para banda militar por ejemplo). Lo cierto es que ejecutaban todo tipo de obras con los ajustes necesarios. A continuación se presenta una muestra de la conformación de la Banda Militar de Alajuela de 1932 donde se puede apreciar la cantidad de músicos.

Fotografía N 1. Banda Milita de Alajuela 1932

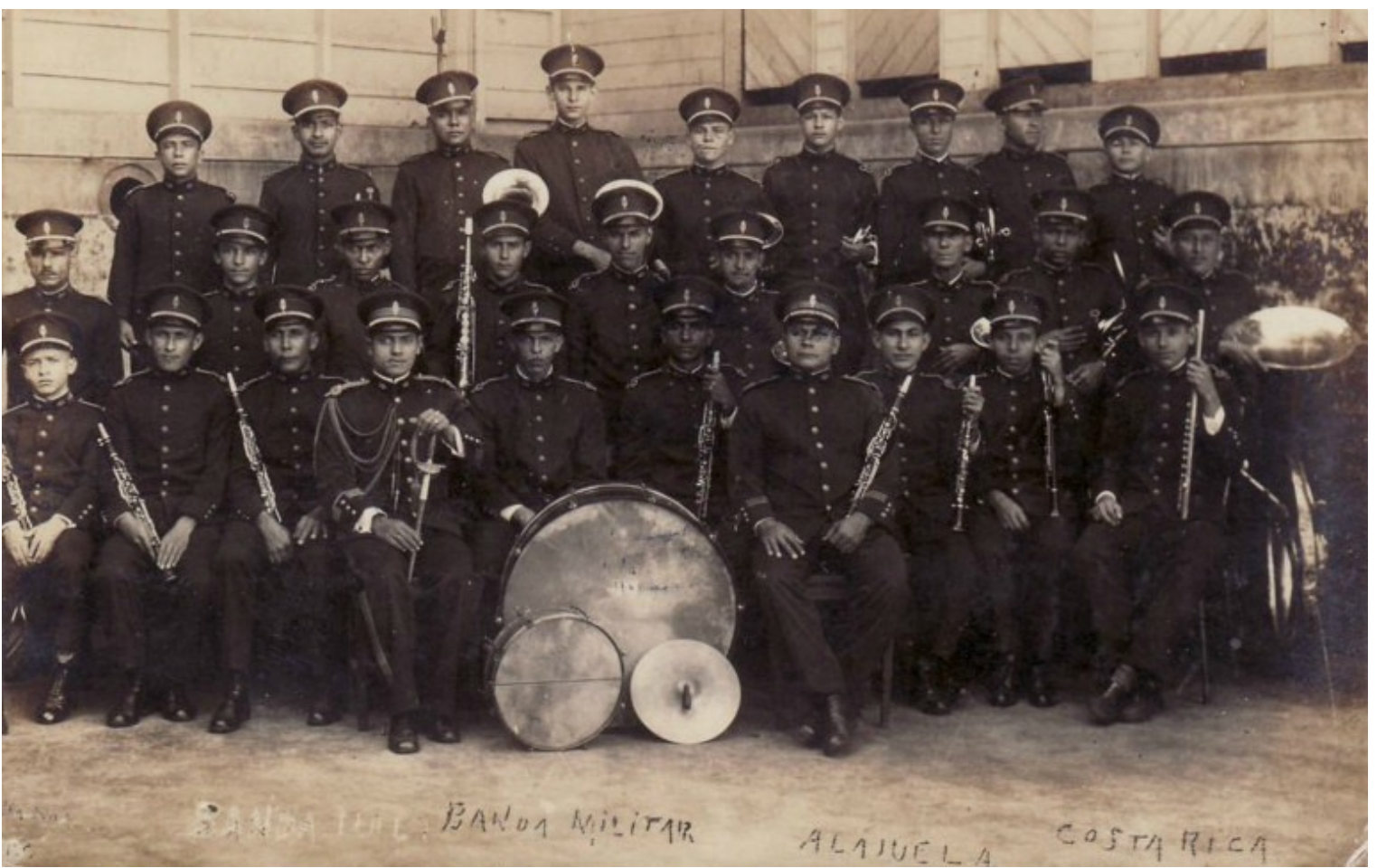

${ }^{33}$ Flores, Julio Fonseca, 300. 
En las últimas páginas del catálogo de música de la Banda Militar de Alajuela, arreglado por Bolívar Quirós en julio de 1931, se encuentra su organización para el año 1932. El cuadro No 1 contiene nombres y apellidos, categorías, instrumentos y tiempo de servicio.

Cuadro No 1. Banda Militar de Alajuela en el año 1932.

\begin{tabular}{|c|c|c|c|}
\hline Nombre & Categoría & Puesto & Años de servicio \\
\hline Manuel Alberto Coto Cedeño & & Director & Doce \\
\hline Otoniel Badilla Rodríguez & & $\begin{array}{l}\text { Músico mayor-Primer } \\
\text { cornetín }\end{array}$ & Diecisiete \\
\hline Lisanías Arroyo, & $\begin{array}{l}\text { Primera } \\
\text { categoría }\end{array}$ & Flauta & \\
\hline Carlos Torres Solano & $\begin{array}{l}\text { Primera } \\
\text { categoría }\end{array}$ & Oboe & Doce \\
\hline Francisco Avilés & $\begin{array}{l}\text { Primera } \\
\text { categoría }\end{array}$ & Primer clarinete solo & \\
\hline Gonzalo Ordeñana & & Primer fliscorno & \\
\hline Amadeo Murillo Campos & & Primer trombón & Siete \\
\hline Teodoro Flores Rubio & & Primer barítono & Dos \\
\hline Francisco Casares Castro & $\begin{array}{l}\text { Segunda } \\
\text { categoría }\end{array}$ & Requinto & Veinticinco \\
\hline Alfonso Hermes Vanegas & $\begin{array}{l}\text { Segunda } \\
\text { categoría. }\end{array}$ & $\begin{array}{l}\text { Segundo clarinete } \\
\text { solo }\end{array}$ & Dos \\
\hline Florencio Vilches & $\begin{array}{l}\text { Segunda } \\
\text { categoría }\end{array}$ & Primer clarinete & Dieciséis \\
\hline Neftalí Castillo & $\begin{array}{l}\text { Segunda } \\
\text { categoría }\end{array}$ & $\begin{array}{l}\text { Segundo-primer } \\
\text { clarinete }\end{array}$ & Cinco \\
\hline Constantino Murillo Umaña & $\begin{array}{l}\text { Segunda } \\
\text { categoría }\end{array}$ & Saxo alto & \\
\hline Edwin Maltés Muñoz & \begin{tabular}{|l|}
$\begin{array}{l}\text { Segunda } \\
\text { categoría }\end{array}$ \\
\end{tabular} & Sax tenor & Ocho \\
\hline Uriel Quesada Álvarez & $\begin{array}{l}\text { Segunda } \\
\text { categoría }\end{array}$ & $\begin{array}{l}\text { Segundo-primer } \\
\text { cornetín }\end{array}$ & Tres \\
\hline Rafael Ángel Espinoza Cubero & $\begin{array}{l}\text { Segunda } \\
\text { categoría }\end{array}$ & Primer alto & Once \\
\hline Abelardo González Sandí & $\begin{array}{l}\text { Segunda } \\
\text { categoría }\end{array}$ & $\begin{array}{l}\text { Bombardón en mi } \\
\text { bemol }\end{array}$ & Doce \\
\hline Francisco Méndez Rojas & $\begin{array}{l}\text { Segunda } \\
\text { categoría }\end{array}$ & $\begin{array}{l}\text { Bombardón en si } \\
\text { bemol }\end{array}$ & Doce \\
\hline
\end{tabular}




\begin{tabular}{l|l|l|l}
\hline \multicolumn{1}{c|}{ Nombre } & Categoría & \multicolumn{1}{c|}{ Puesto } & Años de servicio \\
\hline Sulustio Ávila Cruz & $\begin{array}{l}\text { Segunda } \\
\text { categoría }\end{array}$ & Bombo & Ocho \\
\hline Juan José Leitón & $\begin{array}{l}\text { Tercera } \\
\text { categoría }\end{array}$ & Segundo clarinete & Cinco \\
\hline Francisco Chávez Vargas & $\begin{array}{l}\text { Tercera } \\
\text { categoría }\end{array}$ & Tercer clarinete & Tres meses \\
\hline Aquiles Alvarado Ruíz & $\begin{array}{l}\text { Tercera } \\
\text { categoría }\end{array}$ & Segundo cornetín & Seis \\
\hline Juan Herrera González & $\begin{array}{l}\text { Tercera } \\
\text { categoría }\end{array}$ & Segundo fliscorno & Nueve meses \\
\hline Gonzalo Torres Orta & $\begin{array}{l}\text { Tercera } \\
\text { categoría }\end{array}$ & Segundo alto & Cuatro meses \\
\hline Ernesto Paz Enamorado & $\begin{array}{l}\text { Tercera } \\
\text { categoría }\end{array}$ & Segundo trombón & Cuatro \\
\hline Pedro Núñez Vega & $\begin{array}{l}\text { Tercera } \\
\text { categoría }\end{array}$ & Redoblante & Cinco \\
\hline Luis Solano Solano & $\begin{array}{l}\text { Tercera } \\
\text { categoría }\end{array}$ & Sax barítono & Tres \\
\hline Antonio Cordero Calvo & Aprendiz & Platillero & Nueve meses \\
\hline
\end{tabular}

Como se puede ver en la fotografía № 2, la Banda Militar de San José estaba compuesta por muchos más músicos. Se podría decir que aunque las bandas democratizaron el esparcimiento artístico musical, la provincia de San José tenía la ventaja de poseer un grupo mucho mayor que podía ejecutar obras con la instrumentación completa. Esto supone que las personas de la capital lograron escuchar y conocer instrumentos que no estaban presentes en otras bandas, como el fagot o los timbales sinfónicos, eso será una variable a considerar a continuación en el análisis del contacto de esas agrupaciones con su público. 
Fotografía № 2. Fotografía, Banda Militar de San José, obsequio de Roberto Cantillano a Jesús Bonilla, 28 de mayo de 1939.

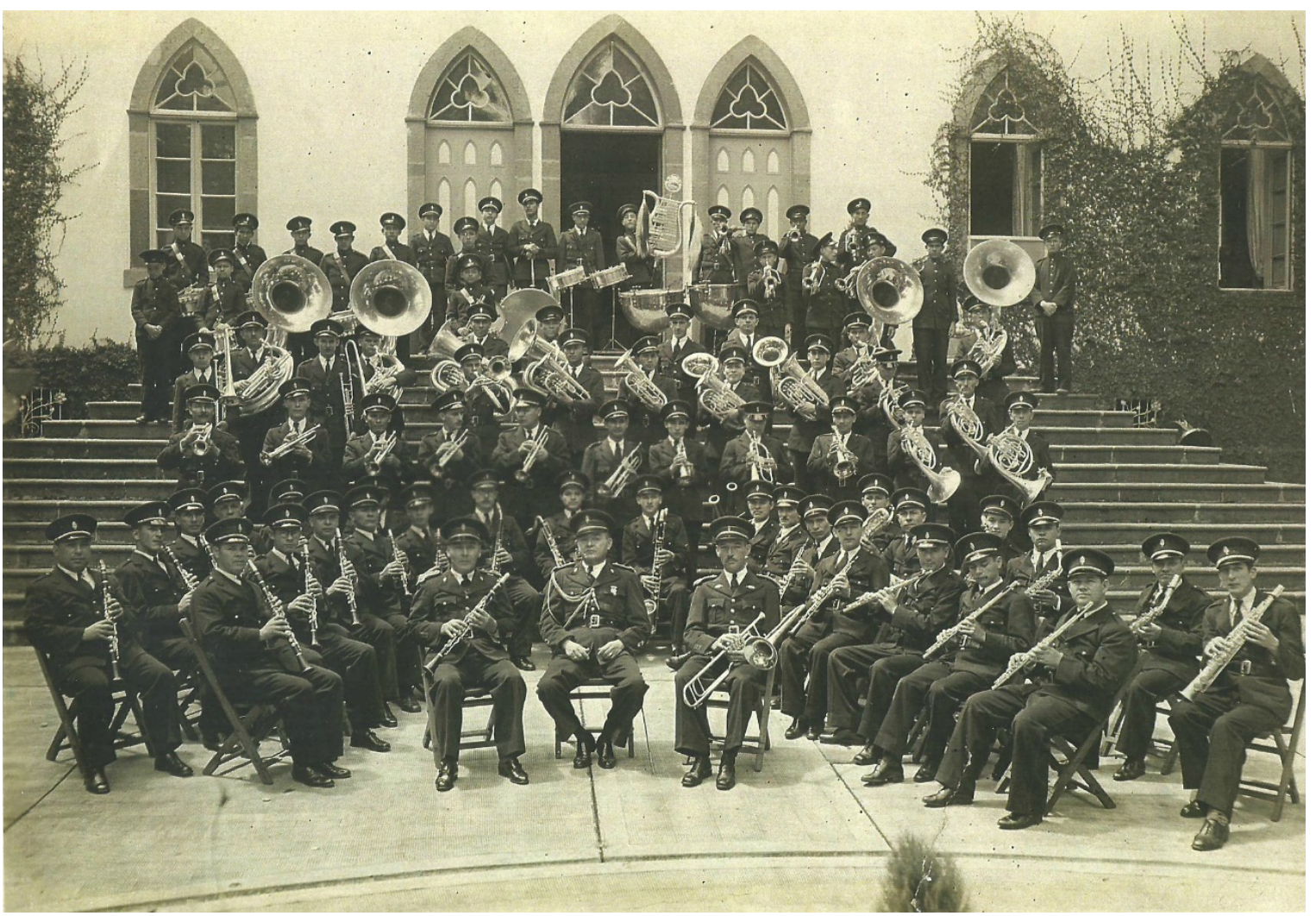

\section{Contacto de la banda militar con la población}

Las publicaciones sobre la música en Costa Rica que han abordado el tema de las bandas militares han brindado información de relevancia. A lo anterior, se debe sumar lo aportado por las "bitácoras de trabajo", ${ }^{34}$ que podrá servir para reconstruir la historia de estos grupos y confrontar las historias de dominio académico y empírico sobre su impacto. Gracias a los contenidos de esos documentos oficiales y el análisis de los datos, se puede definir que las bandas fueron difusoras de música costarricense e internacional y ofrecieron

\footnotetext{
${ }^{34}$ Las siguientes, resguardadas en el archivo de la Banda de Conciertos de Alajuela: Banda Militar de Alajuela. Movimiento disciplinario durante el mes de abril, 1930/ Catálogo de música, Banda Militar de Alajuela año 1936. Arreglado por Juan José Leitón/ Cuaderno de castigos del cuerpo de banda, entregado por la comandancia de plaza el 15 de agosto de 1934 y llevado por Arcelio Chávez/ Libro de programas, 1 de mayo de 1938, Banda militar de Alajuela/ Libro de programas, 1 de agosto de 1951, Banda Militar de Alajuela/ Nuevo régimen 1936-1940 Alajuela, 8 de mayo, Inventario general de la Banda Militar, Movimiento de Altas, Bajas, descensos, traslados, cambios de instrumentos etc., a cargo de Manuel Alberto Coto Cedeño.
} 
presentaciones gratuitas en las siete provincias de Costa Rica; desde 1845 fungieron como instituciones culturales que realizaban actividades artísticomusicales en las comunidades en contacto directo con la población. El Estado costarricense, antes de la creación de la Orquesta Sinfónica Nacional y del Ministerio de Cultura, Juventud y Deportes, impactó con sus políticas culturales a los habitantes por medio de la gestión de las bandas de música militares.

Según se mencionó en el primer artículo publicado ${ }^{35}$, se ha decidido iniciar una discusión que contemple el análisis del contacto de las bandas militares con su público, por medio de las programaciones, de los servicios realizados, la divulgación de estos y la interacción con los oyentes en los distintos eventos. La proyección de la música en general, con sus valores estéticos que se redistribuyen y posicionan, puede ser analizada observando la cultura en relación con el poder, el consumo y la educación musical. En dicha publicación señalamos que

...Todas las sociedades se presentan como espacios sociales, es decir estructuras
de diferencias que sólo [sic] cabe comprender verdaderamente si se elabora el
principio generador que fundamenta estas diferencias en la objetividad. Principio
que no es más que la estructura de la distribución de las formas de poder o de las
especies de capital eficientes en el universo social considerado - y que por lo tanto
varían según los lugares y los momentos. ${ }^{36}$

Si se entiende la cultura como una redistribución de valores y se da por sentado que esos valores los redistribuye la clase dominante o quienes tienen una situación de poder, es posible considerar que la música y conceptos asociados se posicionan en el público que frecuentemente acude a los espectáculos, o servicios diversos de las bandas. Por lo tanto, quienes deciden la programación de obras para los conciertos activan los mecanismos de redistribución. Se llaman mecanismos de redistribución pues el director y el músico mayor (subdirector) son quienes deciden las programaciones. Ellos ya han participado como consumidores y han condicionado un gusto o han interiorizado ciertos valores estéticos que los hacen decidirse por ciertas obras, géneros o estilos de música. El espectador se constituye en consumidor y los mecanismos de distribución continúan actuando, de manera tal que la recepción de valores estéticos (de las obras musicales de diversos estilos y géneros) y conocimiento musical se da incluso de manera automática e inconsciente. Sobre lo anterior, Néstor García Canclini expone:

\footnotetext{
${ }^{35}$ Araya, "La Banda Militar de Alajuela y su papel como difusora de música nacional", 71-97

${ }^{36}$ Pierre Bourdieu, Espacio social y campo de poder. (Barcelona: Ed. Anagrama, 1983), 48-49
} 
Los hábitos y gustos de los consumidores condicionan su capacidad de convertirse en ciudadanos. Su desempeño como tales se forma en relación con los referentes artísticos y comunicacionales, con los entretenimientos y la información preferidos. ${ }^{37}$

Una vez considerado lo anterior, es necesario analizar los fenómenos de redistribución de acuerdo a ciertas variables. Por ejemplo, la situación poblacional del país era muy diferente a la actual y se brindó mayores oportunidades de contacto a quienes vivían cerca de los lugares en donde se realizaron las presentaciones.

La capital del país, San José, todavía no alcanzaba los 90.000 habitantes en 1950, en tanto que los cascos centrales de Alajuela, Cartago y Heredia albergaban, cada uno, menos de 15.000 personas, y las ciudades más pequeñas tendían a oscilar entre 2000 y 5000 almas. El conocimiento personal entre sus moradores era una de las características básicas de estos diminutos universos urbanos, dominados por edificaciones de una sola planta y en los cuales sobresalía el follaje de los árboles en la fotografías aéreas: con sus escuelas, cantinas, iglesias, plazas, cines, mercados, oficinas públicas, fábricas y talleres artesanales, constituían el eje comercial, cultural y administrativo de su entorno agrario. ${ }^{38}$

Como se puede apreciar en la cita anterior, los cascos centrales de cada provincia contaban con menos de 15.000 habitantes antes de 1950 y estas funcionaban como centros comerciales, culturales y administrativos. Además, la dinámica de trabajo de las bandas permanecía con rigurosidad, según lo constatan los libros de programas (bitácoras). Eso quiere decir que los habitantes de la cabecera de cada provincia tenían la oportunidad de acudir a las presentaciones todas las semanas, mientras que los habitantes de los cantones únicamente cuando la banda los visitaba, si se lograba coordinar de manera exitosa. Por ejemplo, entre 1938 y 1946 la Banda Militar de Alajuela ofreció más de mil presentaciones diversas, sin embargo, en ese periodo se presentó pocas veces en otras comunidades alajuelenses, tal como lo muestra el siguiente cuadro:

\footnotetext{
37 Néstor García Canclini, Consumidores y ciudadanos. Conflictos multiculturales de la globalización. (México: Grijalbo, 1995), 147. Artículo "De lo público a lo privado: la americanización de los espectadores. Consumidores del siglo XXI ciudadanos del siglo XVIII

38 Iván Molina, Costarricense por dicha: identidad nacional y cambio cultural en Costa Rica durante los siglos XIX y XX. (San José, Costa Rica. Editorial UCR, 2015), 83.
} 
Cuadro $N^{\circ}$ 2. Presentaciones de la Banda Militar de Alajuela en comunidades alajuelenses entre 1938 y 1946.

\begin{tabular}{|c|c|c|}
\hline Lugar & Frecuencia & Fechas \\
\hline San Mateo & 5 veces & $\begin{array}{l}\text { 20/9/1938, } \\
\text { 20/9/1940, } \\
\text { 20/9/1941, } \\
\text { 20/9/1942, 20/9/1943 }\end{array}$ \\
\hline Orotina & 4 veces & $\begin{array}{l}3 / 8 / 1940,2 / 8 / 1941 \\
3 / 8 / 1944,2 / 8 / 1945\end{array}$ \\
\hline Palmares & 4 veces & $\begin{array}{l}\text { 24/9/1938, } \\
\text { 23/9/1944, } \\
\text { 23/9/1945, 26/1/1946 }\end{array}$ \\
\hline Grecia & 4 veces & $\begin{array}{l}\text { 4/5/1941, 24/9/1941, } \\
\text { 24/9/1942, } \\
\text { 26/12/1943 }\end{array}$ \\
\hline San Ramón & 3 veces & $\begin{array}{l}\text { 30/8/1938,10/2/1939, } \\
17 / 3 / 1944\end{array}$ \\
\hline San Pedro de Poás & 3 veces & $\begin{array}{l}29 / 6 / 1944, \\
29 / 6 / 1945,29 / 6 / 1946\end{array}$ \\
\hline Río Segundo & 3 veces & $\begin{array}{l}\text { 25/7/1941, } \\
\text { 25/7/1942, 25/7/1943 }\end{array}$ \\
\hline Naranjo & $1 \mathrm{vez}$ & $1 / 8 / 1940$ \\
\hline Atenas & $1 \mathrm{vez}$ & $23 / 10 / 1943$ \\
\hline La Guácima & $1 \mathrm{vez}$ & $26 / 11 / 1944$ \\
\hline Tapesco & $1 \mathrm{vez}$ & 15/8/1941 \\
\hline Sarchí & $1 \mathrm{vez}$ & $31 / 10 / 1943$ \\
\hline
\end{tabular}

Como se mencionó antes, la demografía también debe ser considerada, pues el porcentaje de personas impactadas por estos grupos será proporcional a la cantidad de habitantes en un momento dado.

Datos sobre la población de Costa Rica revelan que en 1927 la cantidad de habitantes del país era 489030 y en 1950 subió considerablemente a $859280 .{ }^{39}$

${ }^{39}$ C.I.C.R.E.D. Instituto de investigaciones sociales, La población en Costa Rica (San José Costa Rica: Oficina de publicaciones de la Universidad de Costa Rica, 1976), 8. 
Por otra parte, al 31 de diciembre de 1943 era de 706 598. En las provincias estaba distribuida de la siguiente manera: ${ }^{40}$

Cuadro №3. Distribución de la población de Costa Rica en 1943.

\begin{tabular}{|l|r|l|r|l|r|}
\hline Provincia & Población & $\begin{array}{l}\text { Cantón } \\
\text { central }\end{array}$ & Población & $\begin{array}{l}\text { Capital de } \\
\text { provincia }\end{array}$ & Población \\
\hline San José & 229504 & San José & 88077 & San José & 74872 \\
\hline Alajuela & 148771 & Alajuela & 36605 & Alajuela & 9999 \\
\hline Cartago & 106242 & Cartago & 31926 & Cartago & 9667 \\
\hline Heredia & 53025 & Heredia & 17526 & Heredia & 10331 \\
\hline Guanacaste & 84536 & Liberia & 11578 & Liberia & 3694 \\
\hline Puntarenas & 45727 & Puntarenas & 22427 & Puntarenas & 8265 \\
\hline Limón & 38793 & Limón & 25770 & Limón & 9760 \\
\hline
\end{tabular}

Iván Molina seguramente utiliza el término casco central para referirse a lo denominado en esa época "capital de provincia" en donde se encontraban los parques principales que albergaron los conciertos.

Una vez conocidos los datos de población de esa época y de acuerdo al ejemplo anterior sobre comunidades visitadas por la Banda Militar de Alajuela entre 1938 y 1946, se puede establecer que quienes tuvieron más ventaja para poder escuchar las bandas en 1943, por su cercanía, fueron las 126588 personas de las capitales de cada provincia (17,9\% de la población total de Costa Rica). Esos porcentajes variaron en las provincias con respecto a la población total de cada una: San José, 32,6\%; Alajuela, 6,7\%; Cartago, 9\%; Heredia, 19,4\%; Guanacaste, 4,3\%; Puntarenas $18 \%$ y Limón, $25,1 \%$ Es lamentable no tener a mano datos sobre la cantidad de público asistente a las presentaciones para poder conocer cuántos aprovechaban ese presupuesto destinado por el estado para la música militar.

Por otra parte, los datos de la población de las provincias también son importantes para verificar la disparidad en inversión estatal en música y cultura. Un aspecto que marcó diferencia en la manera de contactar al público, era el

\footnotetext{
${ }^{40}$ Ministerio de Economía y Hacienda. Dirección General de Estadística, Anuario Estadístico de Costa Rica 1943: sección 43a2 demografía. (San José: Ministerio de Hacienda, 1945), 67 http://ccp.ucr.ac.cr/bvp/pdf/anuariocr/an1943/anuario-43-02.pdf
} 
tamaño de las bandas. De acuerdo a la fotografía No 2, se logró notar que la Banda Militar de San José tenía más de setenta músicos en sus filas. No se sabe porque razón, y hasta el día de hoy, las bandas militares del resto de las provincias están conformadas por menos de treinta músicos. Como se pudo observar, la banda de Alajuela no tenía la posibilidad de contar con las filas completas de trompetas, cornos, clarinetes y percusión. Esa desigualdad impidió que lograra ejecutar las instrumentaciones completas de las obras del repertorio internacional europeo y americano. Así por ejemplo, el público escuchó las orquestaciones incompletas y no conoció instrumentos como el fagot, los timbales sinfónicos, entre otros.

Con respecto al posicionamiento de valores estéticos, para efectos de este trabajo se les denominó atributos que diferencian una creación musical de otra por las variaciones en el empleo y desarrollo de las diferentes sonoridades armónicas, melódicas y rítmicas; así como los distintos colores instrumentales. Son considerados por el espectador en su juicio sobre lo que escucha, eso le ocasiona reacciones emocionales en virtud de lo que considere bello. También, son normas estéticas establecidas y posicionadas en diferentes contextos culturales.

En el caso de Costa Rica, muchos ciudadanos, antes de 1950, consumieron valores estéticos por primera vez gracias a las bandas. Se puede definir que ante una densidad de población menor, con menos distractores y difusores de música que los actuales; el consumo de obras, géneros y conceptos musicales en los conciertos de las bandas, se daba de una manera más eficaz y menos competida.

Si se considera, además, la existencia de otros mecanismos de distribución de obras musicales, los cuales afectaban masivamente a la población, como la radio o la televisión, es posible observar lo siguiente: con respecto al acceso de ciertos bienes en 1950, Iván Molina cita a Walter Hernández Valle, quien dice: "Los aparatos que funcionaban con fluido eléctrico... eran muy pocos: si acaso, una modesta cocina o calentador de barro con resistencia; una plancha y, en uno que otro caso, un receptor de radio..." 41 Sobre esto Molina agrega "unos pocos años atrás era casi excepcional..."42 Esa información debe ser ampliada con datos precisos sobre la tenencia de radio y televisión de las poblaciones en

\footnotetext{
${ }^{41}$ Iván Molina, Costarricense por dicha, 97. Citando a, Walter Hernández, Años de primavera. Memorias de un liceísta. San José, (Costa Rica. Editorial Costa Rica, 1995), 70.

42 Molina, Costarricense por dicha, 97.
} 
contacto con las bandas. Sin embargo, siguiendo lo dicho por Walter Hernández, no muchos escucharon las obras musicales del repertorio de las bandas por esos medios de difusión, en especial las obras de autores nacionales o internacionales que no estaban grabadas, de tal manera que muchas piezas musicales proyectadas en las presentaciones, se consumieron y se posicionaron únicamente ahí, tal es el caso de la lista de piezas de autores costarricenses mostrada en los artículos anteriores, extraída del "Libro de programas 19381946" de la Banda Militar de Alajuela.

Otro aspecto a tomar en consideración es la alfabetización, la cual aceleró la tendencia a consumir bienes culturales entre 1890 y 1950.

\begin{abstract}
La penetración de la cultura de masas acorde con la diversificación de los patrones de consumo, se acrecentó a partir de 1950. La experiencia de Costa Rica en este campo fue temprana a lo que contribuyó una alfabetización popular que se profundizó desde fines del siglo XIX. El 90,1\% de los varones urbanos y el 69,9\% de los rurales, y el $82,5 \%$ de las mujeres de la ciudad, y el $56,2 \%$ de las del campo, que vinieron al mundo en todo el país entre 1886 y 1895 , lograron alfabetizarse, aunque la mayoría sólo cursó los primeros grados de escuela. El alfabetismo en ascenso fue la base para que en el periodo 1890-1950 se diera un consumo cada vez más amplio de revistas, periódicos (en particular, de la prensa sensacionalista) y de las novelas de aventuras y del corazón, y contribuyó a que se extendiera el gusto por el deporte (sobretodo el fútbol), la música popular, el teatro y el cine. ${ }^{43}$
\end{abstract}

Los sectores populares de inicios del siglo $\mathrm{XX}$, cada vez más alfabetizados, pronto se descubrieron como consumidores culturales (teatro, cine, deporte, música y periódicos amarillistas, entre otros productos). ${ }^{44}$

Sobre esto se pueden definir dos aspectos en relación con las bandas: el primero, esos grupos estatales fueron parte importante del proceso histórico en educación musical, pues transmitieron conocimientos por medio de sus presentaciones (retretas, recreos, procesiones, misas, desfiles) y de la publicación e impresión de notas de prensa y programas de obras, tal como se verá más adelante. Lo segundo, según las citas textuales anteriores, se consumieron cada vez más revistas y periódicos (material impreso) por lo tanto, había más conocimiento sobre el quehacer de las bandas y sobre la música que proyectaban. Además, sí se acrecentó el consumo de música, especialmente la popular; las presentaciones de las bandas fueron una opción, pues ejecutaron obras de géneros populares, en especial en los conciertos de "música ligera".

\footnotetext{
43 Molina, Costarricense por dicha, 101.

44 Molina, Costarricense por dicha, 97. Citando a Walter Hernández, Años de primavera. Memorias de un liceísta (San José, Costa Rica. Editorial Costa Rica, 1995), 133.
} 
En síntesis, cuanta más alfabetización, más disposición para el consumo cultural. De tal manera que para este periodo de estudio se contempla a un público más educado que el del siglo anterior y más dispuesto a exponerse a eventos culturales como los producidos por las bandas.

Por otra parte, Rafael Cuevas Molina considera que los liberales, en su idea de amalgamar y posicionar su visión de país, requirieron repensar los temas culturales y sociales.

La pregunta crucial en este sentido es: ¿para qué necesitaban los liberales la construcción de una idea de nación y, consecuentemente, de un nacionalismo? La respuesta es: para cohesionar a la población en torno a su proyecto político y económico. El proyecto liberal de cultura comportó dos niveles: uno de diferenciación y otro de homogenización. La diferenciación implicó, en primer lugar, el distanciamiento entre cultura urbana y cultura rural y, en segundo lugar, en una creciente distinción entre la cultura popular y la cultura "de élite". La homogenización se expresó en la aceptación más o menos unánime de una serie de ideas en torno a la nación costarricense. La aceptación de estas ideas no se dio por generación espontánea o por decreto, sino a través de la construcción de un consenso. ${ }^{45}$

A pesar de lo anterior, la diferenciación dada o el distanciamiento entre cultura urbana y cultura rural no fue tan radical en el ámbito de cobertura de las bandas militares, lo mismo con respecto a la homogenización expresada, al distinguir la cultura popular y la cultura de élite. A pesar de las diferencias con la Banda Militar de San José, las bandas del resto de las provincias, por la naturaleza de su trabajo, democratizaron el acceso a la cultura por medio de la música, tanto la popular cómo la culta o académica. Gracias a las bitácoras de trabajo (libros de programas y catálogos de obras), se sabe que ejecutaron piezas de los grandes maestros europeos y latinoamericanos, así como música de corte popular de diversos géneros, estilos y nacionalidades. Además, promovieron la apreciación musical de forma gratuita para todas las personas que quisieran acercarse a los conciertos en los parques. La siguiente fotografía ilustra con ejemplos de varias programaciones lo dicho anteriormente.

${ }^{45}$ Rafael Cuevas, “La cultura en Costa Rica, una permanente construcción”, Asamblea Legislativa Revista Parlamentaria, 6, no 2, (diciembre 1998): 2 
Revista Herencia, Vol. 31 (1), enero-junio, 2018.

143

Fotografía N 3. Página 4 Libro de programas 1938-1946, Banda Militar de Alajuela.

4

Domingo 22 de Inayo 1938

Omisa

Fenspastad en los Alpes Jiantasia Pastaral Klin Suleika Danza Oriental

Recreo

Iranada ¿'ytalienme a Alger

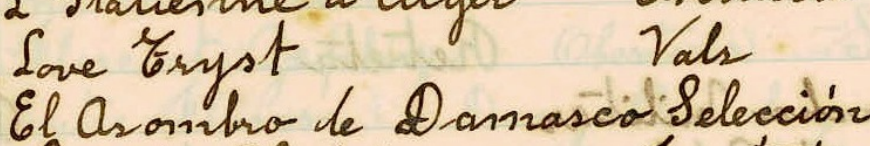
Sweet Child
Prasodoble Lon

Ghertura Rossini

C. Carazo

Surva Sewis

Retretá

- Les Suprimida far la lluvia

Livercoles 25 de Mrayo 1938

Viting-le-Français

Retritar

the Derriére Pensee

Pasodotle

Etasser

Ohesturara

Buot

inuleika masurtio '? Squire Coppelia of Giantasión Delibes

Viemes 27 de mayo 1938

V.

Arabian fix tat is smyde

Viemes 27 de mayo 1938 Retreta

Coronel Cantillano ecteno marchar H. Briceño

Une Demiere Pensee

Obestura Buot

W Stida ou nut estreno

Prasilla Hbitbriceño

+ Sigrantes y Cabezudis Seleceión Caballera Surance Buttresfly intomeno Inctiot Donaldion

ISSN: 1659-0066 
Como lo constata Iván Molina, antes de 1950 la mayoría de la población de las provincias fuera del área metropolitana era considerada rural; por lo tanto, del todo no es cierto que la división entre lo rural y el urbano aplicó para los asistentes a los conciertos de las bandas militares, pues en las provincias de Guanacaste, Puntarenas, Limón, Cartago, Alajuela y Heredia se realizaban los servicios con la misma rigurosidad que en San José, salvo por la desventaja para los habitantes de esas provincias de no poder disfrutar de orquestaciones completas, pues sus bandas eran más pequeñas.

Con respecto a la educación musical, es importante aclarar que esta se propició también en el seno de las bandas militares: hacia adentro con la formación de sus integrantes en la Escuela de Música Militar y hacia afuera en la docencia. Como lo relató Julio Fonseca, varios músicos enseñaban y formaban a otros en escuelas colegios y filarmonías comunales.

En lo que concierne al contacto con el público, se puede decir que una vez que los consumidores están dispuestos a continuar su exposición a los eventos musicales de las bandas, inician un proceso de consumo de conocimiento que les permite apreciar la música, reconocer el lenguaje técnico musical, así como a los diversos autores, obras y géneros musicales. Christopher Small expone al respecto:

El punto donde se aproximan en forma más significativa los dos conceptos gemelos de la relación productor consumidor y del conocimiento como algo esencialmente externo a quien conoce y aparte de él, se encuentra en el campo de la educación... ${ }^{46}$

Los productores (compositores, directores, gestores) están en contacto con los consumidores constantemente por medio de las presentaciones en donde se ofrecen obras que serán consumidas. El receptor, a través de su primera audición y de la lectura de programas de mano, o por medio de las explicaciones de las obras; se acerca al conocimiento. Dicho de otra forma, el conocimiento lo aproxima al compositor, a su lenguaje; a su idea estética, estilística; a su ideología, a su filosofía. En el contexto de las bandas militares este hecho es relevante pues como ya se dijo, eran las únicas instituciones gubernamentales dedicadas a ofrecer presentaciones musicales a la población de todas las provincias.

${ }^{46}$ Christopher Small, Música, Sociedad, Educación (Madrid: Alianza Editorial, 1989), 185. 
Varios conciertos eran anunciados por la prensa, otros eran comentados posteriormente en periódicos y revistas, algunos tenían los respectivos programas de mano que seguramente servían también de anuncios. Tal como se ha mencionado, esos impresos contenían información sobre las obras que se programaron. Por ejemplo: Las siete palabras de Cristo, de Alejandro Monestel, estrenadas tres en versión para banda un miércoles en el parque central de San José, bajo la dirección de Roberto Cantillano en 1939.47

Fotografía N 4. Programa impreso, Banda Militar de San José

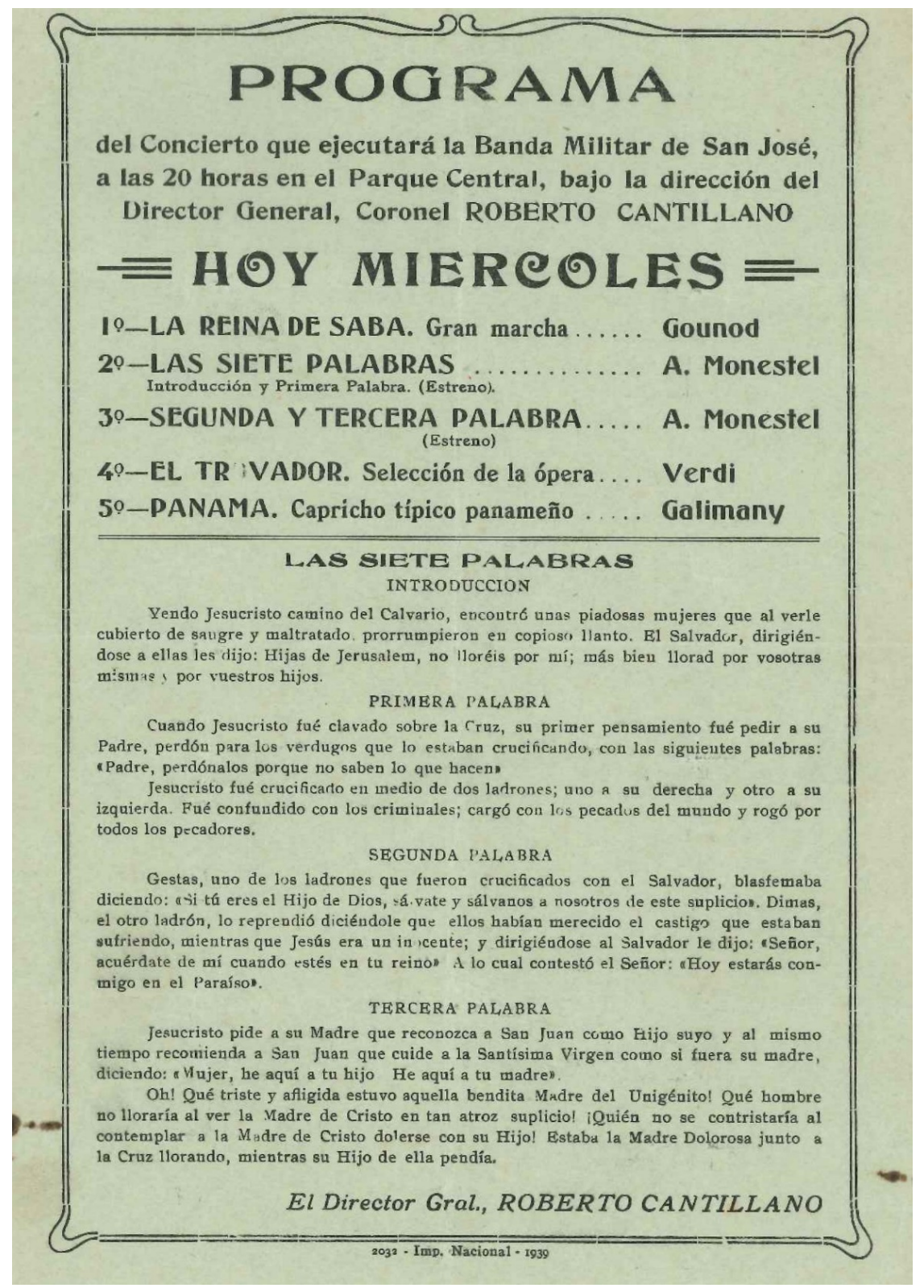

47 Los programas impresos se encuentran en archivos personales de quienes los han conservado. Los utilizados en este trabajo fueron brindados por Jenny Bonilla. 
Otro concierto, de un miércoles en 1939, contiene también varias obras, entre ellas, tres estrenos: Resurrección y ascensión de Alejandro Monestel, y el pasillo Ensueños de Manuel Alberto Coto. En este programa de mano se da una explicación de las obras Resurrección y ascensión de Monestel, Mefistófeles, selección de la ópera de Arrigo Boito y de la Rapsodia nicaragüense de Gilberto Vega, que también fue estrenada ese día.

Fotografía № 5. Programa impreso, Banda Militar de San José.

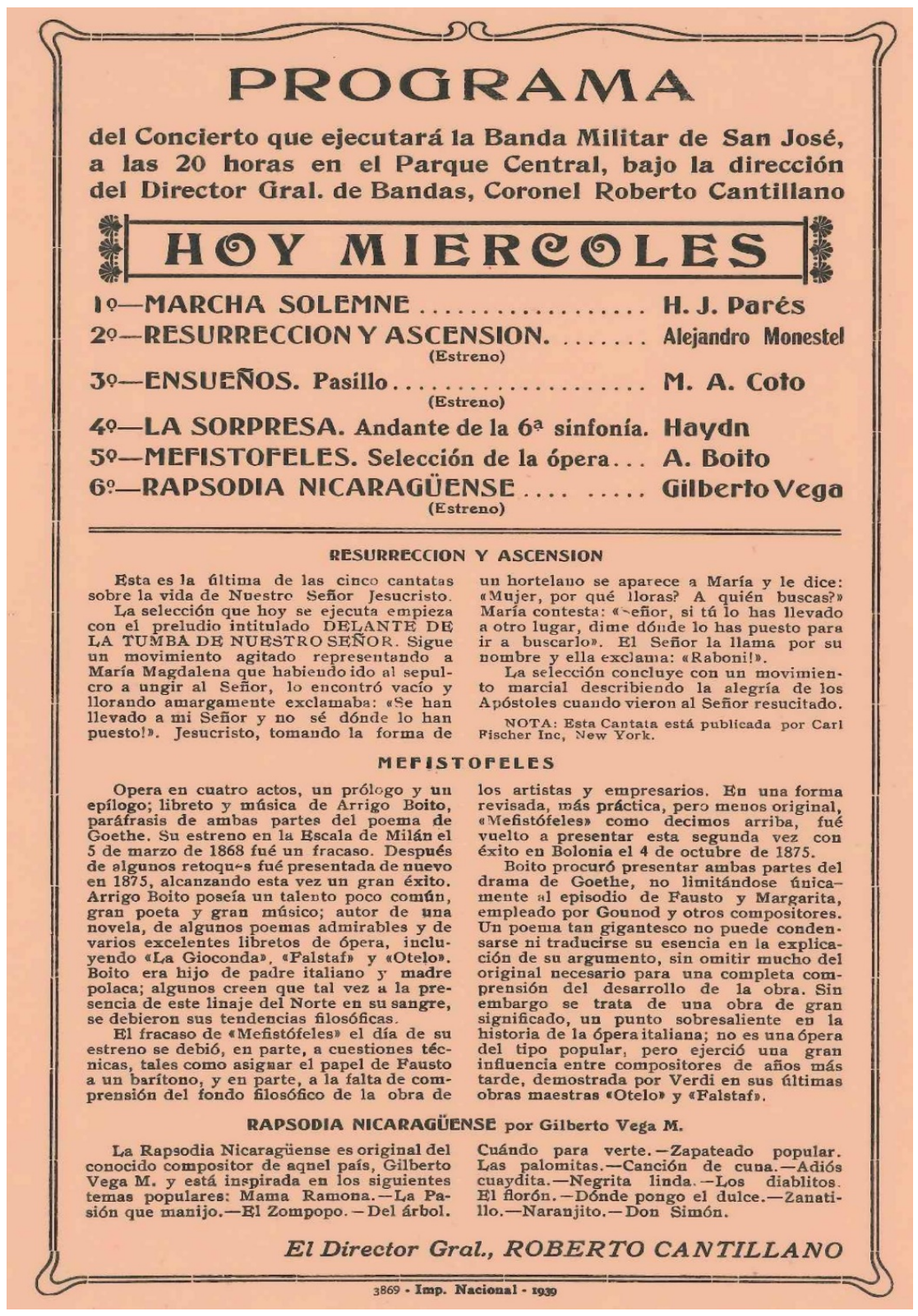


Es evidente que las personas que asistieron a los conciertos, o en general, quienes tenían acceso a estos programas de mano, pudieron aprender sobre las obras musicales, los compositores y la historia de la música; de tal manera que se formaron en el ámbito de la apreciación musical. Un programa de mano del miércoles 16 de junio de 1937 también explica sobre las obras Nocturno número uno, de Jesús Bonilla estrenado ese día y sobre la Fantasía napolitana de Boccalari.

Fotografía Nº 6. Programa impreso, Banda Militar de San José, 16 de junio de 1937

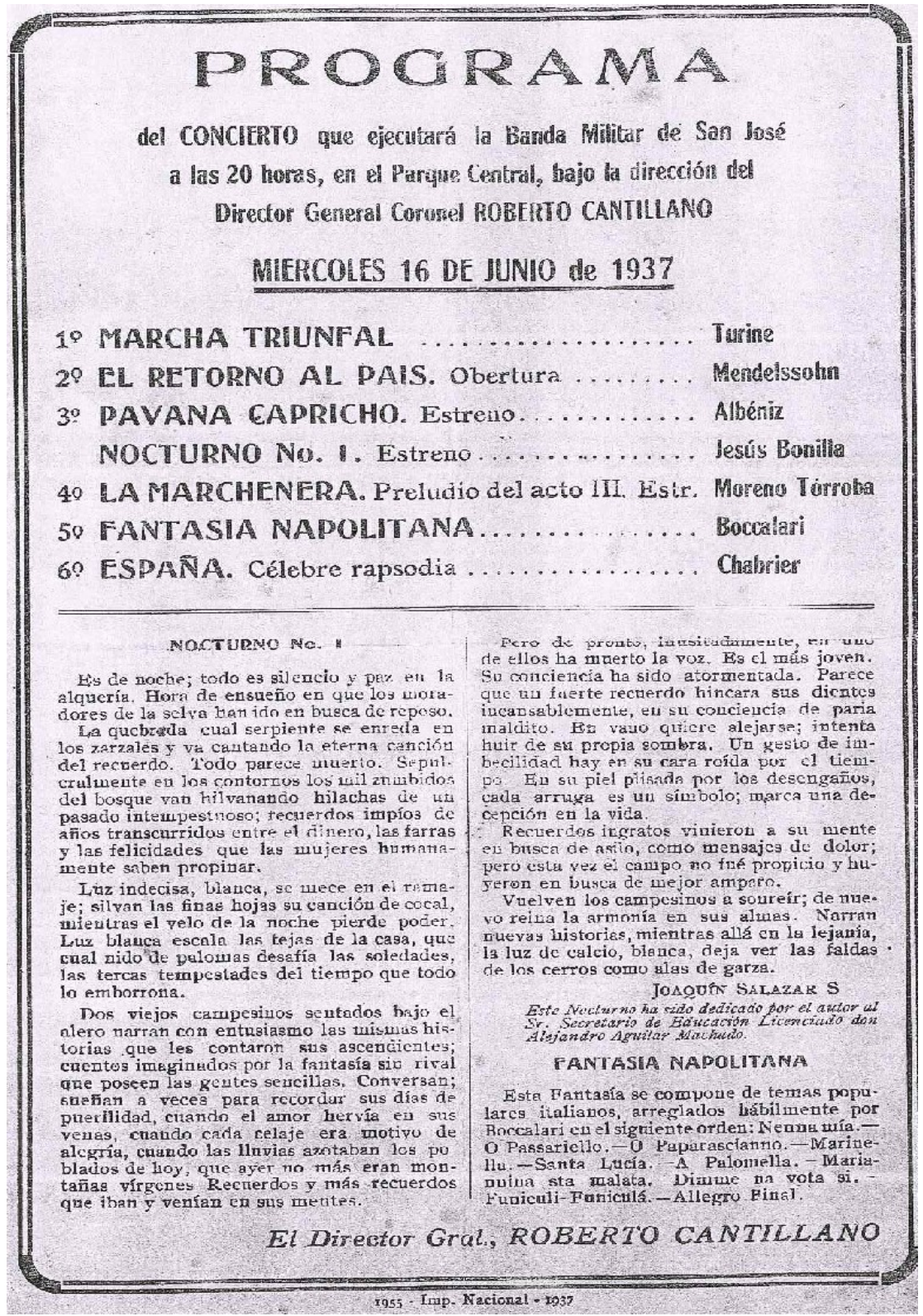


Por otro lado, vale la pena mencionar algunos aspectos de la educación para el patriotismo. Es necesario señalar que en las escuelas y colegios se enseñaban canciones e himnos patrios, a conocer y respetar los símbolos, los héroes y se educó a la población para que entendiera la importancia de las efemérides. Las bandas cumplieron un papel protagónico en este sentido, pues debían participar en las actividades patrióticas más importantes en donde les correspondía tocar los himnos respectivos a cada una y ejecutar obras nacionales que resaltaran la identidad nacional. El hecho de ser bandas militares y la ejecución constante de marchas, toques de ordenanza e himnos patrios las posicionaba como herramientas indispensables en la educación para el patriotismo. En un concierto con música nacional realizado el jueves 15 de septiembre de 1938 en la retreta se tocaron las siguientes obras: ${ }^{48}$

Cuadro No 4. Obras interpretadas en concierto el 15 de setiembre de 1938.

\begin{tabular}{l|l|l}
\multicolumn{1}{c|}{ Compositor } & \multicolumn{1}{c|}{ Género } & \multicolumn{1}{c}{ Obra } \\
\hline Eduardo Cuevas & Obertura & El Marqués de Talamanca \\
\hline Alejandro Monestel & Intermezzo & Después de las bodas \\
\hline Carlos María Gutiérrez & Mazurca & Celia \\
\hline Julio Fonseca Gutiérrez & Pot pourri & Aires ticos \\
\hline Julio Fonseca Gutiérrez & Vals & Leda Vals Intermezzo \\
\hline
\end{tabular}

Otro ejemplo se encuentra en un programa de mano del concierto de gala que ejecutó la Banda Militar de Alajuela el domingo 24 de septiembre de 1939, con música de compositores costarricenses, dirigida por el Director General de Bandas, coronel Roberto Cantillano.

48 Libro de programas, 1 de mayo de 1938, Banda militar de Alajuela, 20. 
Fotografía No 7. Programa impreso, Banda Militar de Alajuela, 24 de septiembre de 1939.

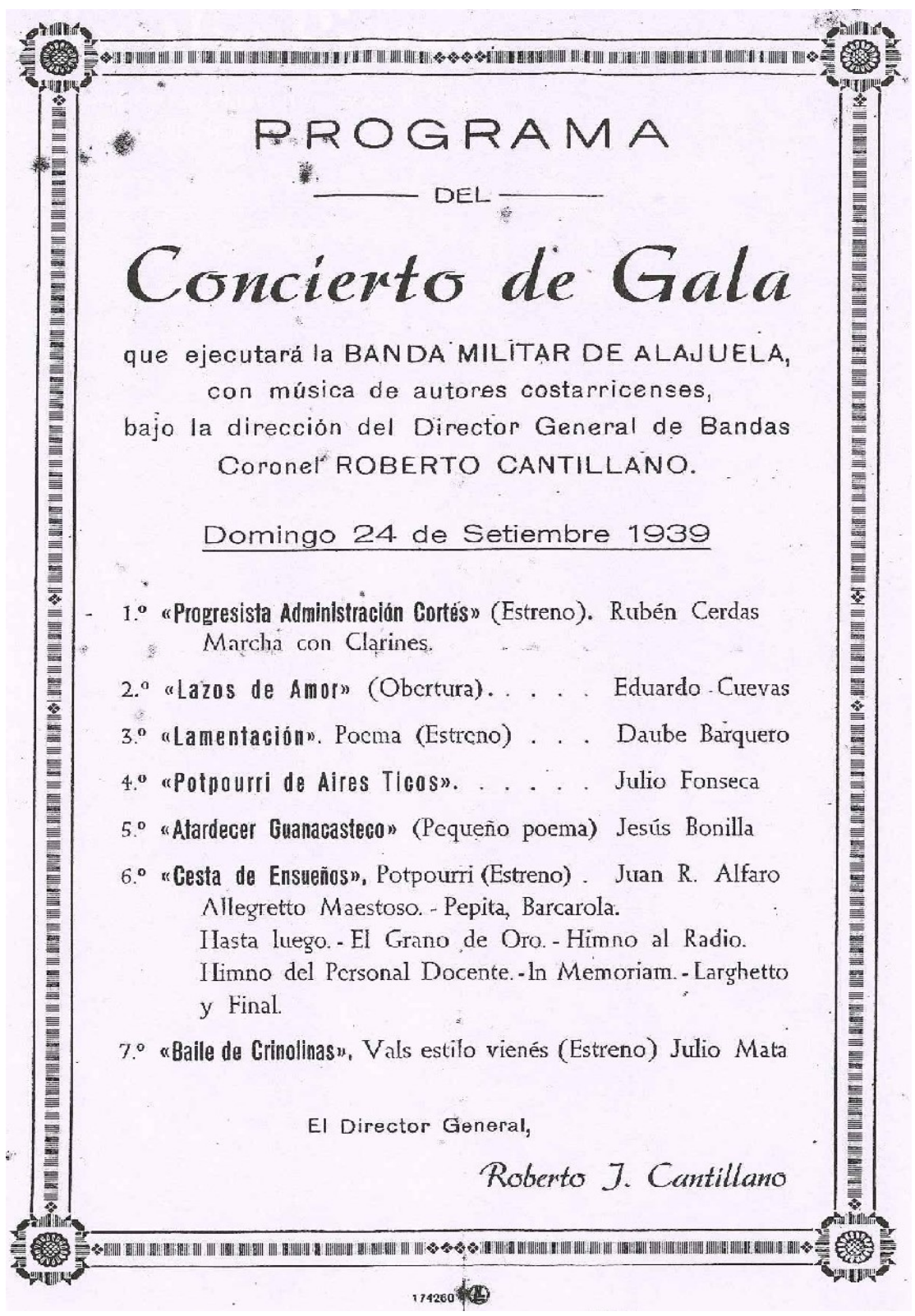

La música nacional ayudó a generar una idea colectiva de autenticidad y de coherencia en el ámbito cultural y artístico, aunque las condiciones políticas siempre afectaron el alcance de las bandas y su proyección. Desde épocas pasadas, las bandas fueron posicionando valores, conocimiento y patriotismo; siendo estas una herramienta para tal fin, puesta en marcha, según las iniciativas 
de quienes ostentaron la mayor cuota de poder en la Dirección General de Bandas y en el Gobierno Central. En las "bitácoras" de las bandas militares se encuentran las evidencias de las decisiones, acciones y estrategias de quienes estaban al mando; por ejemplo: cantidad de servicios, lugares de las presentaciones, repertorios; y en favor de exaltar el patriotismo: conciertos con obras costarricenses, presentaciones en festividades tradicionales y populares, la ejecución de marchas e himnos patrios. Se cumple así lo definido por Jaime González Dobles:

La conciencia patriótica valora las conductas en función de ideales de existencia. Cada pueblo, como cada ser humano, tiene que mantener una conducta lo más auténtica posible: lo más coherente consigo mismo. La autenticidad se crea y se consolida en una respuesta creativa ante las potencialidades de humanización de cada realidad humana. Pero, en la convivencia humana, los factores personales, culturales o morales, son condicionados por la globalidad del quehacer social. El pasado inserta en forma casi inconsciente sus valores en las estructuras de nuestra conciencia. Por tal razón, la dinámica de la realidad patriótica genera una tensión dialéctica entre las demandas culturales y las condiciones políticas, económicas o sociales: se debate siempre entre las aspiraciones y las posibilidades, entre las declaraciones y las intenciones de los diversos participantes. ${ }^{49}$

El quehacer de las bandas militares en épocas pasadas y en la actualidad, ha ayudado a sostener una conciencia patriótica. Eso ha permitido que la nación y sus habitantes mantengan valores comunes y autenticidad, todo en función de ciertos ideales, establecidos por quienes tienen el poder de decisión y de gestión. Esa autenticidad se logra por medio de establecer y proyectar la música nacional. Sin embargo, los valores nacionales también han sido condicionados por la globalidad; por ejemplo, los valores estéticos consumidos provenientes de otras latitudes como Europa, Estados Unidos o países grandes de Latinoamérica que han logrado exportar su estética musical a través de sus ritmos y géneros musicales.

Por otra parte, el legado del pasado, como lo afirmó González Dobles, ya viene con estructuras de conciencia insertadas de forma casi inconsciente, eso se ha denominado redistribución de valores (estéticos y culturales). Para tal propósito las bandas han sido herramientas que se debaten entre sus aspiraciones y las decisiones de los gobernantes.

\footnotetext{
49 Jaime González, La patria del tico: interpretación del ser costarricense. (San José Costa Rica: Logos editorial, Editorial Antares, 1995), 24-25.
} 


\section{Conclusiones}

El texto brinda conceptos y datos históricos elementales con el objetivo de acercar la historiografía de las bandas militares costarricenses a los lectores. La información es suficiente para abordar una discusión sobre ese ámbito de estudio, el cual no ha sido eje central de los trabajos investigativos sobre la música en Costa Rica en la primera mitad del siglo XX.

Los datos, ejemplos y comentarios quedan disponibles para alentar a reflexiones específicas y más profundas. Además, nuevas temáticas irán surgiendo, gracias a la amplitud del ámbito de estudio y a la riqueza documental que está en exploración.

Valores estéticos, conocimiento y patriotismo se posicionaron en el público que asistió a las presentaciones de las bandas militares por medio de la proyección de música y conceptos asociados. El análisis de las razones que motivaron a esas agrupaciones a acentuar la conciencia patriótica, aplica para los valores y el conocimiento.

La realidad política, económica y social ha permitido ciertas aspiraciones y posibilidades, por esa razón no se ha logrado brindar iguales oportunidades a los habitantes de cantones y distritos alejados de los centrales. Además, las bandas de las provincias siempre aspiraron completar sus filas, tal como lo ha logrado la Banda Militar de San José. Eso es una aspiración y una declaración; no obstante, las posibilidades han sido otras, determinadas por las intenciones de quiénes están al mando en el gobierno, quienes no han querido brindar a las provincias, el mismo presupuesto destinado a la capital.

Las bandas han estado presentes mayoritariamente en las capitales de provincia desde que existen. El contacto con la población está condicionado a todas las variables discutidas anteriormente: poder, posicionamiento, consumo, demografía, competencia mediática, decisiones administrativas e intenciones relacionadas con el patriotismo.

Existen más variables que marcaron desigualdad con respecto a la presencia de las bandas en diferentes grupos humanos. Los aportes de este trabajo deben estimular la realización de estudios comparativos, objetivos, y cuantitativos, con respecto al alcance en el tiempo de las instituciones gubernamentales más antiguas que han llevado música a los costarricenses; junto con valores estéticos, conocimiento y patriotismo, para que se haga justicia y se valore lo hecho desde una perspectiva social y cultural. 


\section{BIBLIOGRAFÍA}

Acevedo, R. y Guevara Á. (2007). La música tradicional de Guanacaste. Una aproximación escrita. San José Costa Rica: Editorial de la Universidad de Costa Rica.

Araya, M. (2015). El Jazz en la música para vientos. Discusiones analíticas en torno a Rhapsody in blue de George Gershwin y Pasillo enredao de Vinicio Meza. Universidad de Costa Rica - Sede de Occidente, Revista Pensamiento Actual 15, N. ${ }^{\circ} 25,(2015):$ 121-145.

Araya, M. (2016). La Banda Militar de Alajuela y su papel como difusora de música nacional. Análisis de las bitácoras de trabajo 1938-1946. Introducción y resultados preliminares. Universidad de Costa Rica-Sede de Occidente, Revista Pensamiento Actual 16, N. ${ }^{\circ}$ 27, 71-97.

Araya, M. (2017). La Banda Militar de Alajuela y su papel como defensora de la música nacional entre 1938-1946. Análisis de las bitácoras de trabajo. Universidad de Costa Rica, Revista Herencia 30, N. ${ }^{\circ}$ 1, 154-176. https://revistas.ucr.ac.cr/index.php/herencia/article/view/29921

Bourdieu, P. (1996). Raisons pratiques. París: Seuil, coll. Points.

Cordero, E. (1981). Julio Mata. San José: Ministerio de Cultura, Juventud y Deportes, Dirección de Publicaciones.

Cuevas, R. (1998). "La cultura en Costa Rica, una permanente construcción". Revista Parlamentaria 6, N. ${ }^{\circ}$ 2, diciembre, 151-168.

C.I.C.R.E.D. Instituto de investigaciones Sociales. (1976). La población en Costa Rica. San José, Costa Rica: Oficina de publicaciones de la Universidad de Costa Rica.

Fennell, F. (2009). Time and the winds, a Short History of the Use of Wind Instruments in The Orquestra, Band and The Wind Ensamble. Northland Music Publishers.

Flores, B. (1978). La música en Costa Rica. San José: Editorial Costa Rica. 
Flores, B. (1973). Julio Fonseca. Datos sobre su vida y análisis de su obra. San José, Costa Rica: Ministerio de Cultura, Juventud y Deportes.

García, N. (1995). Consumidores y ciudadanos. Conflictos multiculturales de la globalización. México: Grijalbo.

González, J. (1995). La patria del tico: interpretación del ser costarricense. San José Costa Rica: Logos Editorial, Editorial Antares.

Goñi, G. (2008). Roberto Cantillano Vindas: compositor, director y flautista domingueño. La Retreta 1, $N^{\circ} . \quad 3$. http://laretreta.net/0103/articulos/cantillano.html

Hernández, W. (1995). Años de primavera. Memorias de un liceísta. San José, Costa Rica: Editorial Costa Rica.

Khalili, E. (2009). Gustav Holst's Suite In E-Flat, OP. 28: A comparative Analysis of the Original Manuscript and Later Editions. An adapted online version of a paper submitted in partial fulfillment of the requirements for the Master of Music degree in Instrumental Conducting. The Wind Repertory Project. http://www.windrep.org/Articles:First_Suite\#PART_II_.E2.80.93_HOLST.E2.80.9 9S_1909_MANUSCRIPT:_A_DETAILED_ANALYSIS

Latham, A. (2008). Diccionario enciclopédico de la música. México D.F: Fondo de Cultura Económica.

Le Franc, R. (2009). La familia Morales: músicos por tradición. San José, C.R: Editorial UCR.

Mayor, B. (2011). "Harmoniemusik," Sinfonía Virtual, No 21. http://www.sinfoniavirtual.com/revista/021/harmoniemusik.php

Meléndez, C. (1979). Manuel María Gutiérrez. San José, Costa Rica: Ministerio de Cultura, Juventud y Deportes. Depto. de Publicaciones.

Ministerio de Economía y Hacienda. Dirección General de Estadística. (1945). Anuario Estadístico de Costa Rica 1943: sección 43² demografía. San José: 
Ministerio de Hacienda, 1945. Disponible en: http://ccp.ucr.ac.cr/bvp/pdf/anuariocr/an1943/anuario-43-02.pdf

Molina, I. (2015). Costarricense por dicha: identidad nacional y cambio cultural en Costa Rica durante los siglos XIX y XX. San José, Costa Rica: Editorial Universidad de Costa Rica.

Monestel, Y. (2012). La gran aventura musical de Alcides Prado. San José, Costa Rica: Lara Segura y Asociados.

Prado, A. (1942). Apuntamientos sintéticos sobre la historia y producción musical de Costa Rica. San José: Imprenta Nacional.

Sagot, C. (1982). Música y Significados. Heredia: Editorial de la Universidad Nacional.

Segura, P. (2001). Desarrollo musical en Costa Rica durante el siglo XIX. Las Bandas militares. Heredia: Editorial de la Universidad Nacional.

Small, C. (1989). Música, Sociedad, Educación. Madrid: Alianza Editorial.

Svatec, L. (1986). Juan Loots y las bandas de música militar. San José: Ministerio de Cultura Juventud y Deportes. Instituto del libro.

Vargas, M. C. (2004). De las fanfarrias a las salas de concierto: música en Costa Rica, 1840-1940. San José, Costa Rica: Editorial de la Universidad de Costa Rica.

Zaldivar, M. (2006). Costarricenses en la música. Conversaciones con protagonistas de la música popular 1939-1959. San José, Costa Rica: Editorial de la Universidad de Costa Rica.

Zaldivar, M. (2005). Imágenes de la música popular costarricense 1939-1965. San José, Costa Rica: Editorial de la Universidad de Costa Rica.

\section{Fuentes primarias}

Acuerdo Número XCVII. Archivo Nacional de Costa Rica, julio de 1885.

Banda Militar de Alajuela. (1951). Libro de programas, 1 de agosto de 1951. 
Banda Militar de Alajuela. (1938). Libro de programas, 1 de mayo de 1938.

Banda Militar de Alajuela. (1936). Catálogo de música, año 1936. Arreglado por Juan José Leitón.

Banda Militar de Alajuela. (1934). Cuaderno de castigos del cuerpo de banda, entregado por la comandancia de plaza el 15 de agosto de 1934 y llevado por Arcelio Chávez.

Banda Militar de Alajuela. (1930). Movimiento disciplinario durante el mes de abril, 1930.

Banda Militar de Alajuela. (1905). Inventario de útiles pertenecientes a la Banda Militar de Alajuela. Primera fecha indicada en la página 4 del libro, 1905.

Banda Militar de Alajuela. (s.a.). Nuevo régimen 1936-1940 Alajuela, 8 de mayo, Inventario general de la Banda Militar, Movimiento de Altas, Bajas, descensos, traslados, cambios de instrumentos etc., a cargo de Manuel Alberto Coto Cedeño.

Decreto LXIII. Colección de Leyes y Decretos, folios (208-209), 24 de diciembre de 1845. 
Revista Herencia, Vol. 31 (1), enero-junio, 2018. 